\title{
Initial Development and Testing of Microcontroller-MQ2 Gas Sensorfor University Air Quality Monitoring
}

\author{
Brawner Brian L. Heyasa ${ }^{1}$ and Van Ryan Kristopher R. Galarpe $*^{2}$ \\ ${ }^{I}$ Electronics Engineering Department, College of Engineering and Architecture, University of Science and \\ Technology of Southern Philippines, 9000 Philippines \\ ${ }^{2}$ Faculty, Department of Physics, College of Science and Mathematics, University of Science and Technology of \\ Southern Philippines, 9000 Philippines \\ Corresponding author: vanryangalarpe@gmail.com
}

\begin{abstract}
Typical air quality monitoring system involved the use of expensive instruments often accessed through the Philippines Department of Environment and Natural Resources (DENR), leading to limitedlocale based air quality monitoring system. To address the need this study was conducted utilizing microcontroller (arduino-uno)-MQ2 gas sensor. The initial stage included preliminary development of premade devices, coding, and testing on site. The testing was conducted in the University of Science and Technology of Southern Philippines (USTP)-Science complex on March, 2017 with preselected dates. Result showed Rs/Ro ratio within the appreciable range for air quality. Overall, the study served as neo monitoring system for air quality locally and potential use can be maximized. However, it is preliminary in nature and needing improvement.
\end{abstract}

Keywords: microcontroller, arduino, $M Q 2$ gas sensor

\section{Introduction}

The lack of well-equipped facilities needed for air quality monitoring especially in urbanizing communities resulted to dependency on government reports (e.g. Department of Environment and Natural Resources-DENR). Often these reports do not cover all regions for air quality monitoring. Thus, in recent years these drawn researchers to develop new technologies for air quality monitoring typically low cost and efficiently faster. The use of microcontroller-gas sensor device had been studied elsewhere (Al-Haijaet al., 2013; Jaladiet al., 2017; Bhattacharjeeet al., 2012; Abraham and Li, 2014) which may include indoor air quality monitoring (Yu and Lin, 2015; Kim et al 2015; Preethichandra, 2013) and others with wireless applications (Putra et al., 2013; Oathmanet al., 2013).Conveniently, microcontroller is well suited for air quality sensing owing to its access both for non-experts and experts. Although selected studies(Nograleset al., 2014; Cortez et al., 2015; Heredia et al., 2015; Mercado, 2013; Seseet al., 2016; Balmeset al., 2015) in the Philippines locally use this technology, few had been known to its relevance for rapid air quality monitoring in the academic environment. It is with this purpose this study was conducted in the locality of the University of Science and Technology of Southern Philippines (USTP)-Science Complex. The main objective of this study was to develop a microcontroller-MQ2 gas sensor device from pre made components and test its application in a chemical or allied sciences laboratory of USTP. These were set as objectives in order to extrapolate a qualitative estimate of air quality in laboratory facility/building in a university set-up.

\subsection{Framework of the study}

\section{Materials and Methods}

The study was descriptive in nature. It tries to develop a microcontroller-MQ2 gas sensor from premade parts and preliminarily test its functionality in the locality of USTP-Science complex. This was anchored from the studies of Nograles et al. (2014) and Al-Haijaet al. (2013). The MQ2 gas sensor can detect carbon monoxide (CO) and smoke althoughit is capable of sensing other gases (http://www.seeedstudio.com/depot/datasheet/MQ-2.pdf). The schematic diagram is shown in Figure 1.

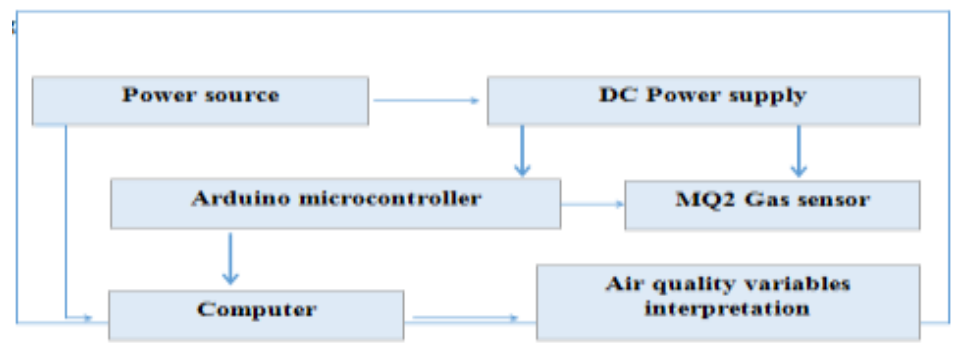

Figure 1. Schematic diagram of the microcontroller-MQ2gassensor 


\subsection{Software and hardware development}

The main hardware of the developed gas sensor included microcontroller arduino and MQ2 gas sensor (refer to Figure 2).Arduino-Uno R3 (designed in Italy) was used as the microcontroller device. The P/N 80031414-1 MQ-x gas sensor kit was used as the MQ2 gas sensor device (manufactured in the Philippines, www.e-gizmo.com). The MQ2 gas sensor is typically used in gas leakage for detecting LPG, i-butane, propane, methane, alcohol, hydrogen, smoke, and carbon monoxide. Further details on these hardware is discussed in the succeeding sections ((https://www.pololu.com/file/download/MQ2.pdf?file id=0J309; Liu, 2014). The coding of the microcontroller-arduino software was based from the MQ2 gas sensor data sheet (http://www.seeedstudio.com/depot/datasheet/MQ-2.pdf). Refer to Figure 3-4 for the specific codes for Rs and Rs/Ro. These served as qualitative estimate of the air quality of the studied site.
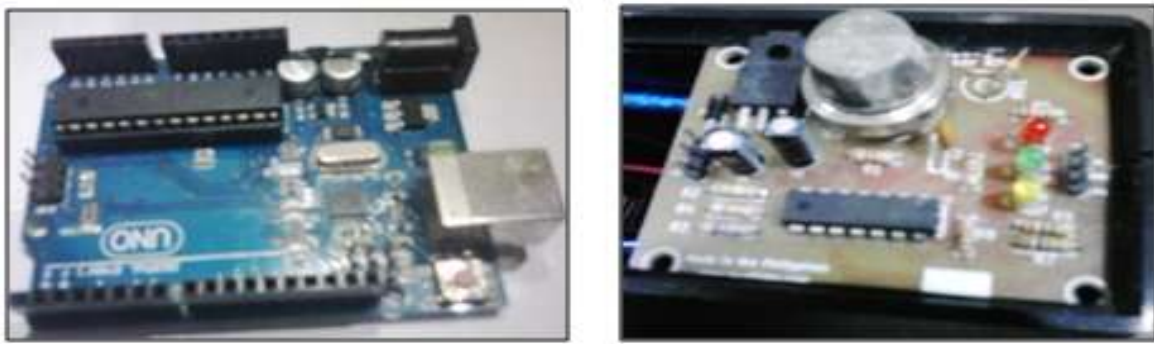

Figure 2. a) Microcontroller-arduino and b) MQ2 gas sensor

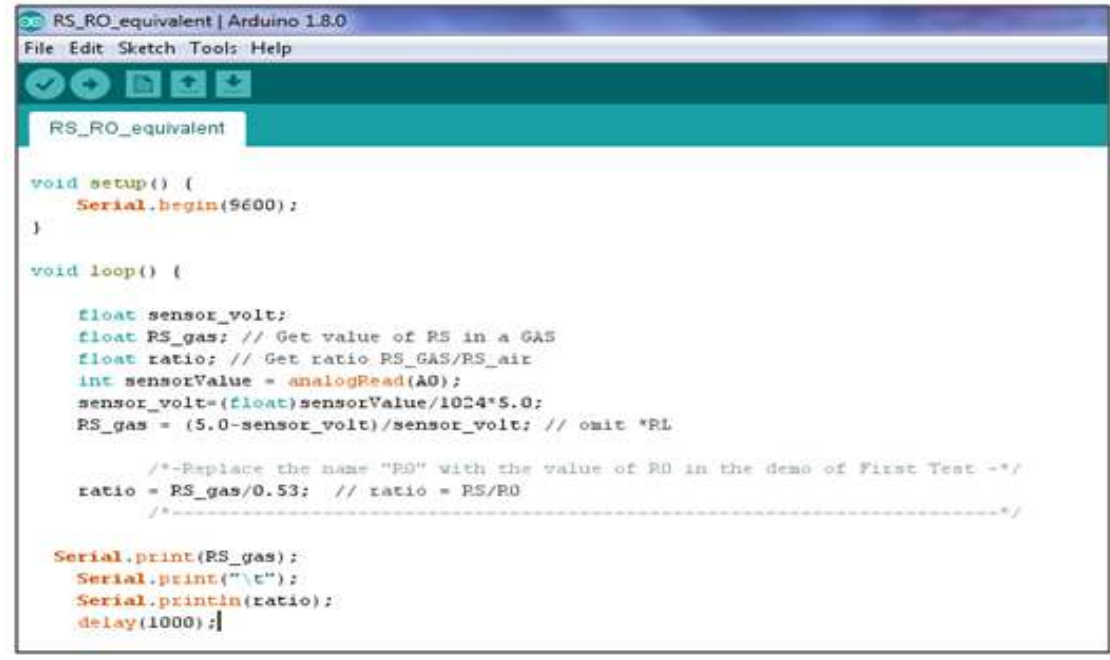

Figure 3. The microcontroller code/program for the RS/RO ratio

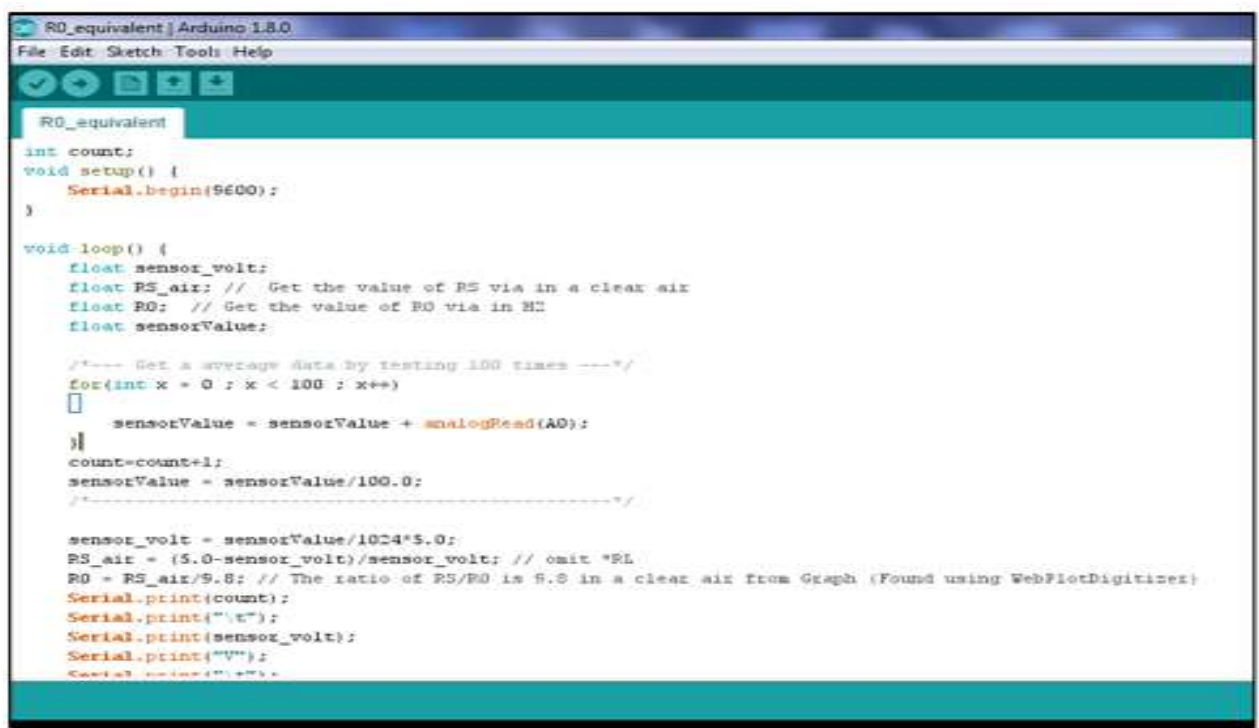

Figure 4.The microcontroller code/program for the RS 


\subsection{MQ2 gas sensor specifications}

MQ-2 gas sensor has high sensitivity to LPG, propane, hydrogen, methane, CO, and other combustible means. It is with low cost and suitable for different application. A typical sensitivity characteristic of MQ2 is presented on Figure 3. The coordinate means resistance ratio of the sensor characteristics. The y-axisis the resistance ratio (Rs/Ro) whereas the $\mathrm{x}$-axis is concentration of gases. The Rsrefers to the sensor resistance to different gases whereas Ro means resistance of the gas to 1000ppm. (Jaladiet al., 2017;Liu, 2014).

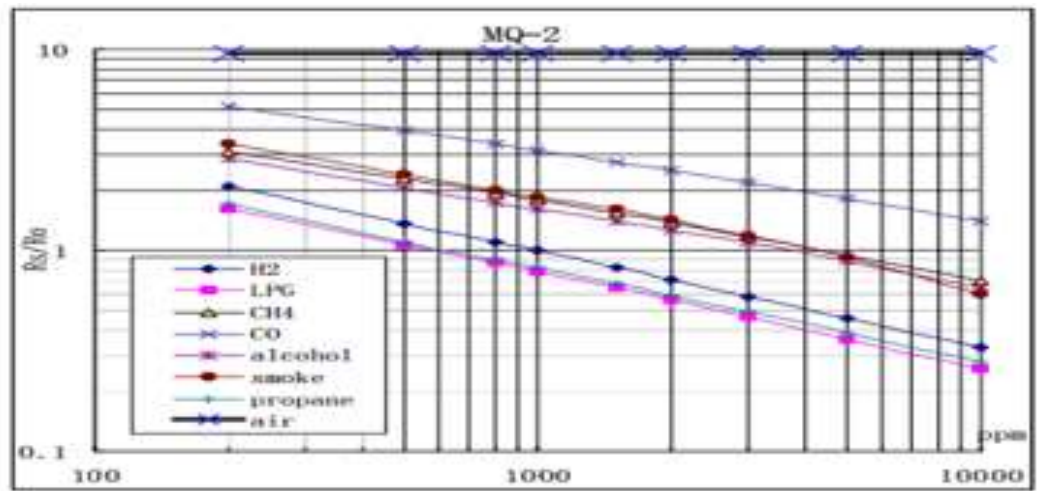

Figure 5.MQ2 gas sensor sensitivity (https://www.pololu.com/file/download/MQ2.pdf?file_id=0J309; Liu, 2014)

\subsection{Study site for testing}

The preliminary testing was conducted in the Science Complex of USTP. The presence of chemical testing and allied sciences laboratory (see Figure 6) which may generate potential gases (speciation of MQ2 gas sensor) made the site fit for the study. However, due to logistical constraints preselected sampling dates were observed.
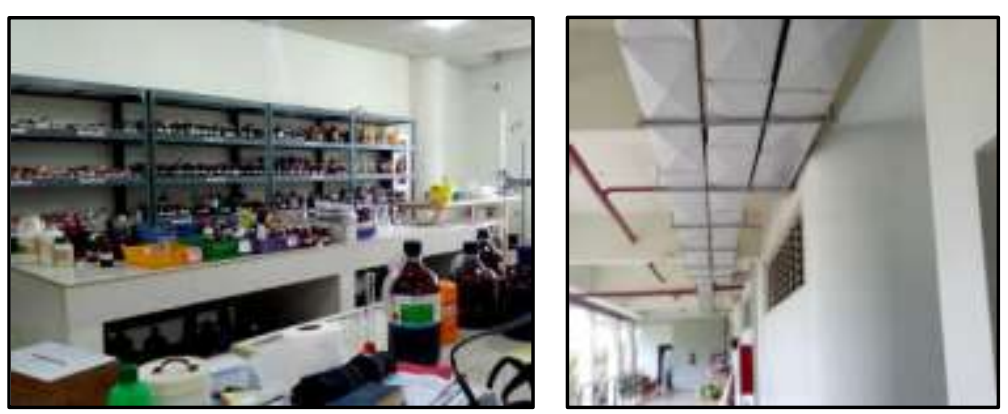

a

b

Figure 6.Selected laboratories in the USTP-Science Complex: a) chemical heating/testing laboratory for thesis; c) gas outlet system at the third floor of the complex-Physics laboratories (photo taken by JovitVestil)

\subsection{Development of air quality monitoring system device}

\section{Results and Discussion}

The complete system is shown in Figure 7. The specific components are listed below:

1. Arduino Microcontroller: this is the core component of the design. Arduino is a flexible programmable hardware platform designed for artists, designers, tinkerers, and the makers of things. Arduino's little blue circuit boardoriginally taking its name from a local pub in Italy. Usually these Arduino-based projects require little to no programming skills or knowledge of electronics theory and commonly packaged as small handy items (Riley, 2012; Al-Haijaet al., 2013).

2. MQ2 Gas sensor: is one of the series of semiconductor Gas Sensors that is used mainly for gas (such as CO) leak detection for houses, workshops, commercial building, Fire, Safety detection system as well as a gas leak alarm. MQ-2 has many features such as: High sensitivity, Fast response, Wide detection range, Stable performance and long life, Simple drive circuit (Al-Haijaet al., 2013; http://www.seeedstudio.com/depot/datasheet/MQ-2.pdf). 
3. Resistance Circuitry: Resistance value $(5 \mathrm{~K} \Omega)$ of $\mathrm{MQ}-2$ is difference to various kinds and variousconcentration gases. When using these components, sensitivity adjustment is very necessary (AlHaijaet al., 2013)

4. Current Regulator Circuit: this electric circuit is needed to regulate the amount of current used to heat and operate the MQ-2 sensor as well as to adjust the sensitivity of the sensor for better calibration readings.

5. Light Emitting Diodes: two LEDs used as indicators (Al-Haijaet al., 2013)

6. Plastic Enclosure: to hold the connected components of the design as one package (Al-Haijaet al., 2013).

7. Power supply: the Extech 382202 constant voltage/current digital DC power supply with dual LCD was used as the power generator.

8. Computer; to record data detected by the device
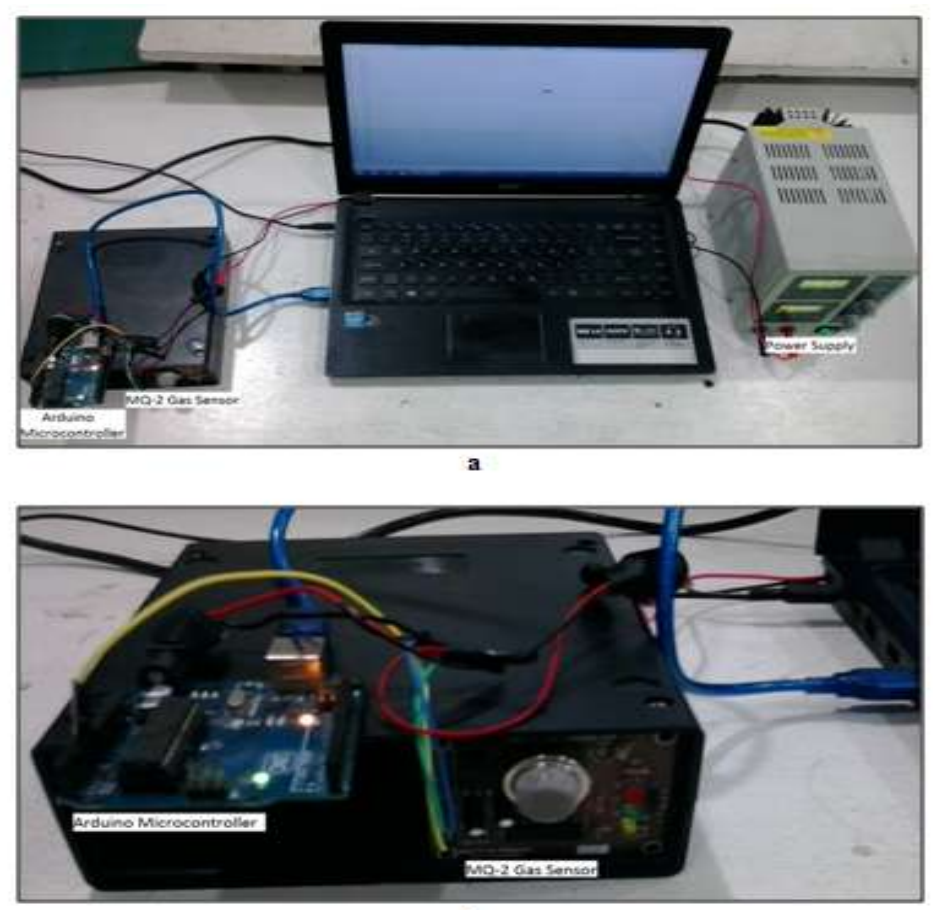

Figure 7.The proposed air quality monitoring system device a) the overall set-up; b) the arduino and MQ2 gas sensor

\subsection{Rs/Ro vs. time}

The developed microcontroller-MQ2 gas sensor can qualitatively determine Rs/Ro (http://www.seeedstudio.com/depot/datasheet/MSQ-2.pdf; Bhattacharjeeet al., 2012; Nograleset al., 2014; Liu, 2014) ratio of the studied site. This was set as rough estimate of air quality to be determined under the specification of MQ2 gas sensor. Purposively, sampling period covered March, 2017 of preselected time and dates presented in Figures 8-10.

Overall, the Rs/Ro ratios ranged 4-10 indicating that potential concentrations were below $1000 \mathrm{ppm}$ of the gases detected. Hypothetically the lesser or minimal is the source of smoke the lower is the voltage output, which may explain the relatively comparable Rs/Ro in all sampling periods. Moreover, a specific gas concentration was not determined and a qualitative Rs/Ro was determined as preliminary testing for the microcontroller-gas sensor device. Nograles et al. (2014) provided calculation equations for CO (Equation 1) and smoke (Equation 2) concentration determination. However, despite the attempt to calculate the specific $\mathrm{CO}$ and smoke concentrations, respectively, the determined values fall outside the MQ2 specification range.

Equation (1)

$y=-7.6 e+002 * x 3+8.7 e+003 * x 2-3.3 e+004 * x+4.1 e+004$

Equation (2)

$\mathrm{y}=-1.3 \mathrm{e}+003 * \mathrm{x} 3+9.9 \mathrm{e}+003 * \mathrm{x} 22.5 \mathrm{e}+004 * \mathrm{x}+2.1 \mathrm{e}+004$ 


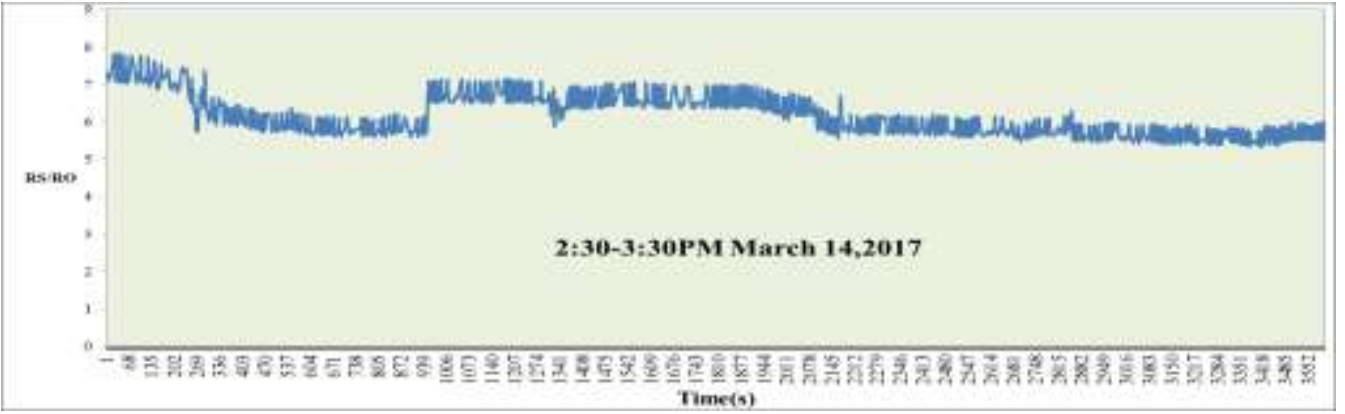

a

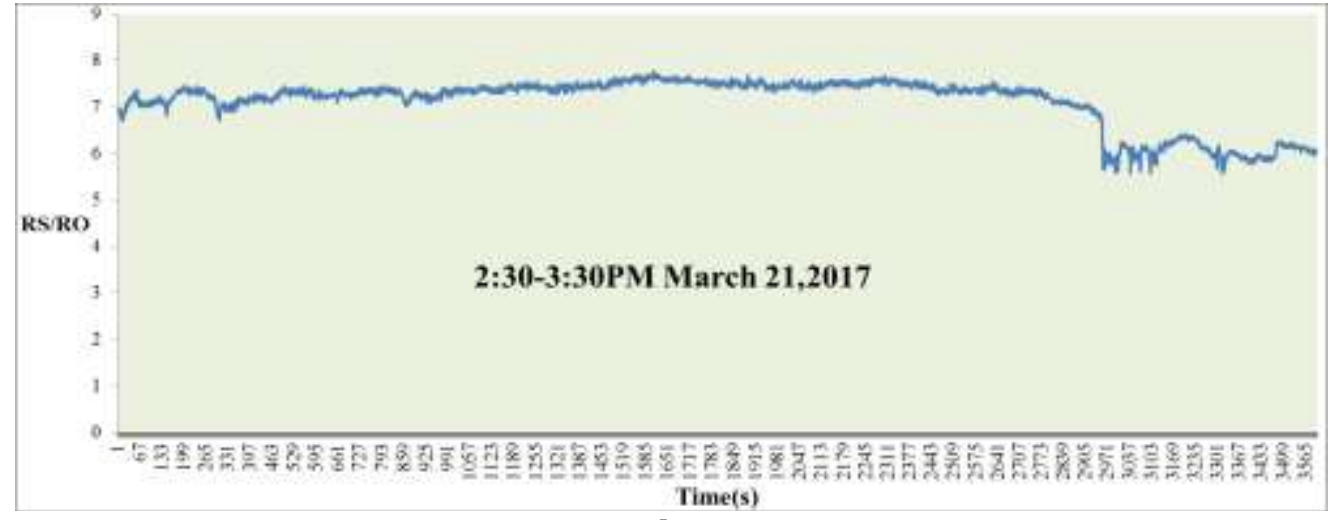

b

Figure 8.Rs/Ro vs time data collected on 2:30-3:30 PM of a) March 14, 2017 and b) March 21, 2017

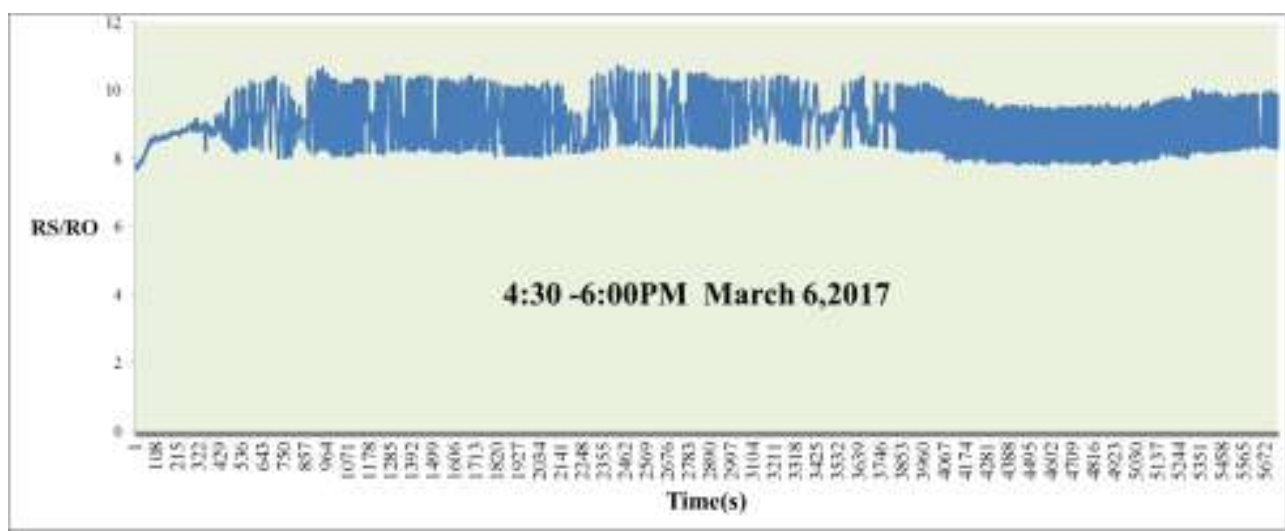

$\mathbf{a}$

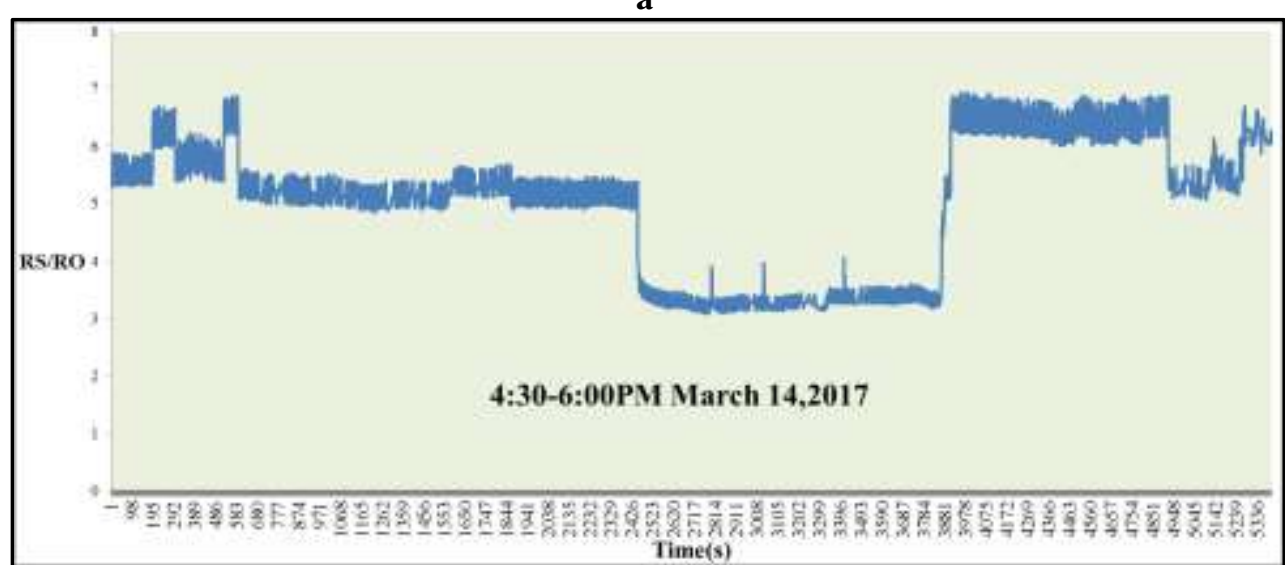

b 


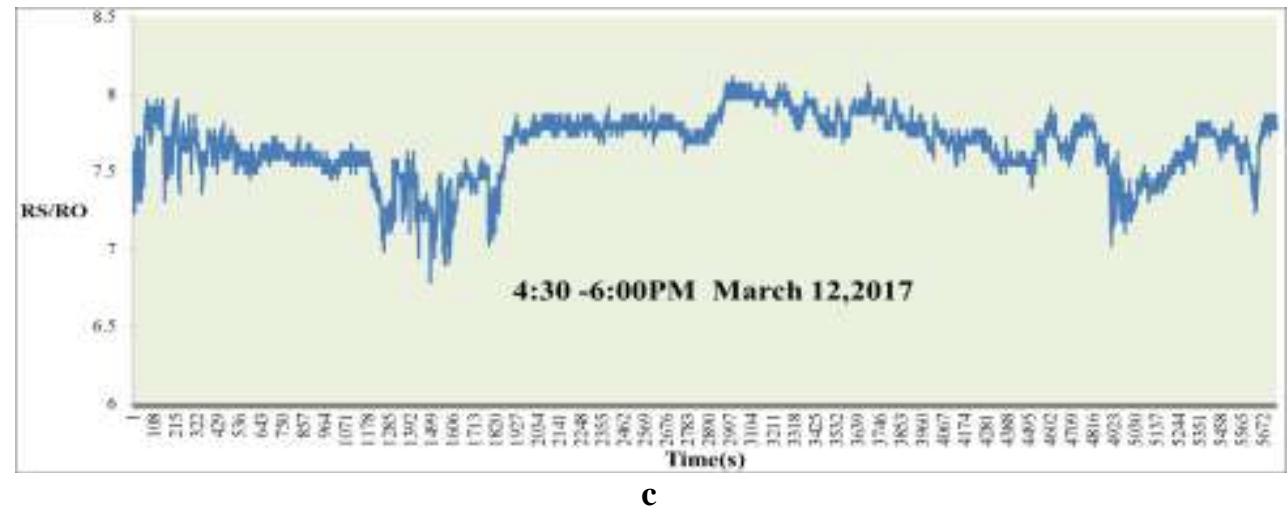

Figure 9.Rs/Ro vs time data collected on 4:30-6:00 PM of a) March 6, 2017, b) March 12, 2017, and c) March 14,2017

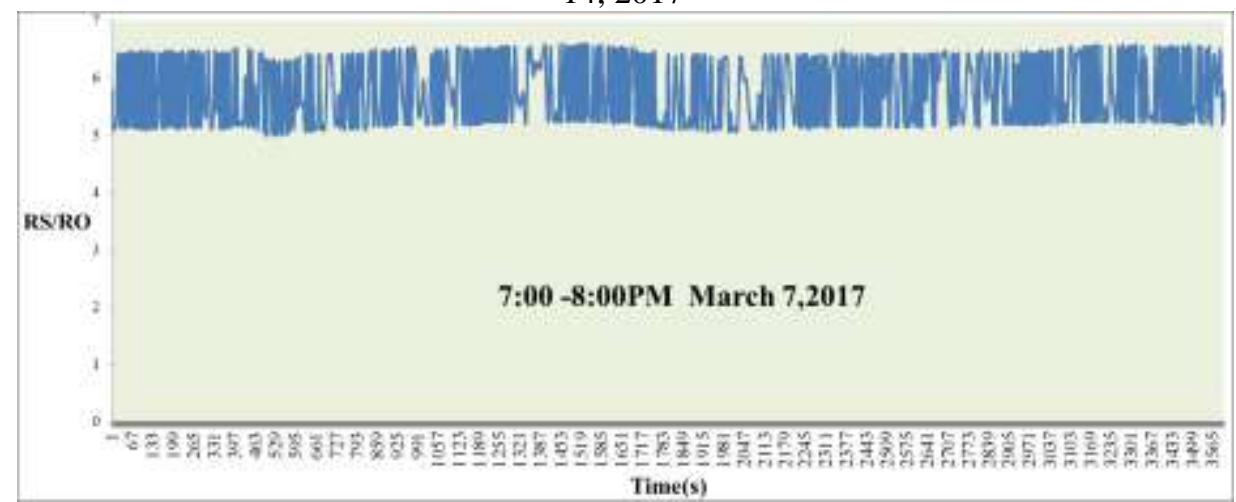

a

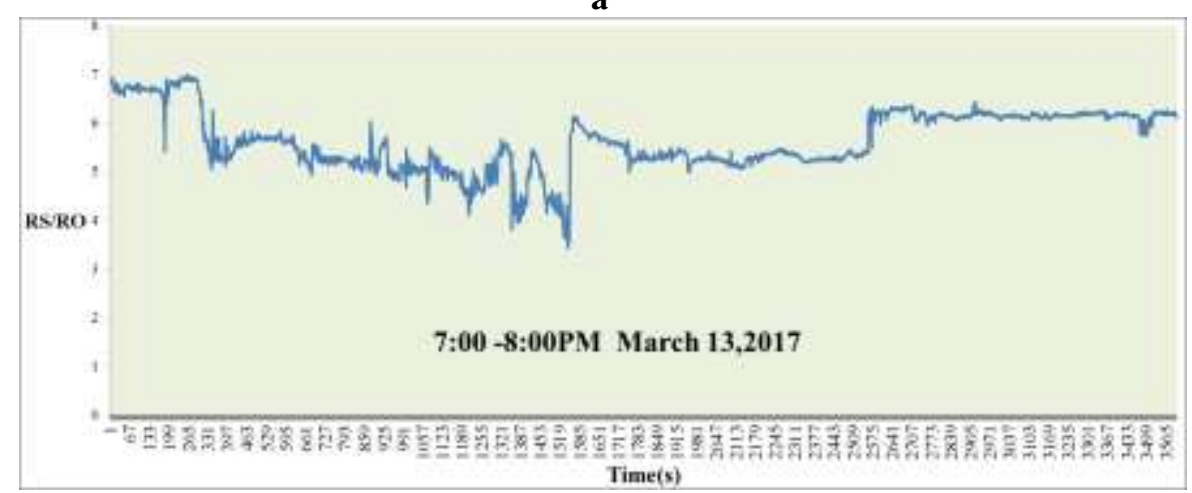

b

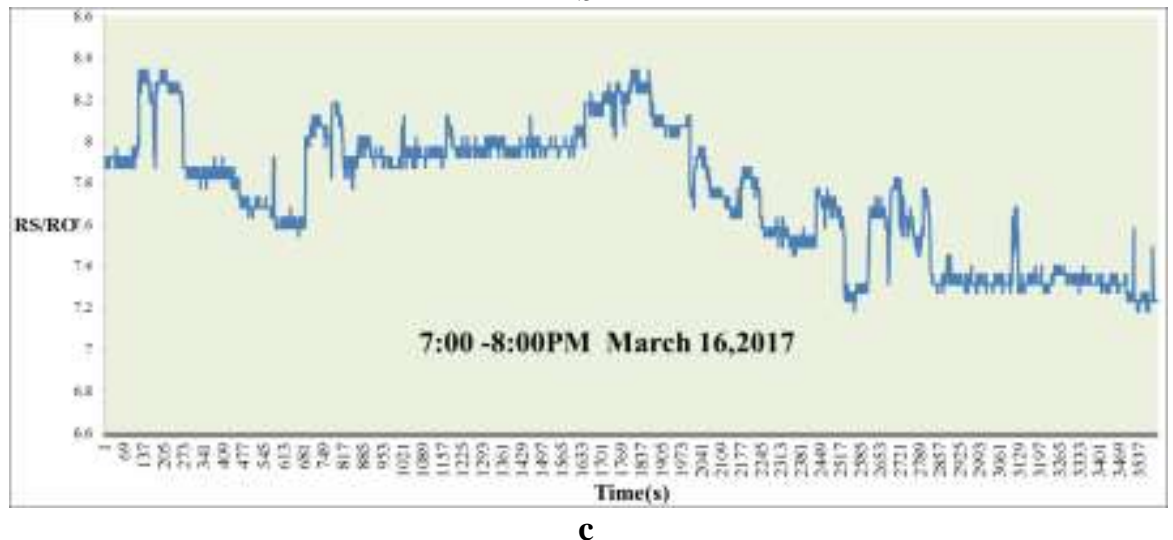

Figure 10.Rs/Ro vs time data collected on 7:00-8:00 PM of a) March 7, 2017, b) March 13, 2017, and c) March 16,2017 


\section{Conclusion}

Overall the low cost developed microcontroller (arduino uno)-MQ2 gas sensor was functioning within the specifications of the sensors sensitivity. Preliminary testing showed no inference for determined Rs/Ro of gases on studied site, implicating acceptable air quality. The design however needs improvement and calibration for convenient application sampling on the study site.

\section{Acknowledgement}

The technical help by the Department of Physics, College of Science \& Mathematics, USTP is acknowledged.

\section{References}

[1] Abraham, Sherin, and Xinrong Li. "A cost-effective wireless sensor network system for indoor air quality monitoring applications." Procedia Computer Science 34 (2014): 165-171.

[2] Al-Haija, Q. A., Al-Qadeeb, H., \& Al-Lwaimi, A. (2013). Case Study: Monitoring of AIR quality in King Faisal University using a microcontroller and WSN. Procedia Computer Science, 21, 517-521.

[3] Balmes, K. V., Chua, J. M. T., De Jesus, M. A. O., Tan, K. C. O., \&Bandala, A. A. (2015, December). Utilization of sensor network for combustible gas detection and monitoring implemented in house hold. In Humanitarian Technology Conference (R10-HTC), 2015 IEEE Region 10 (pp. 1-6). IEEE.

[4] Bhattacharjee, D., Chakraborty, G., \&Choudhury, S. (2012). Environment Sensing and Energy Efficient Smart Sensor Switching. International Journal of Computer Applications, 50(23).

[5] Cortez, C. D., Bato, F. C., Bautista, T. J. G., Cantor, J. M. G., Gandionco III, C. L., \& Reyes, S. P. (2015). Development of formaldehyde detector. International Journal of Information and Electronics Engineering, 5(5), 385.

[6] Jaladi, A. R., Khithani, K., Pawar, P., Malvi, K., \&Sahoo, G. (2017). Environmental Monitoring Using Wireless Sensor Networks (WSN) based on IOT.

[7] Kim, J. J., Jung, S. K., \& Kim, J. T. (2010).Wireless monitoring of indoor air quality by a sensor network. Indoor and built Environment, 19(1), 145-150.

[8] Heredia, A. P. D., Cruz, F. R., Balbin, J. R., \& Chung, W. Y. (2016, November).Olfactory classification using electronic nose system via artificial neural network.In Region 10 Conference (TENCON), 2016 IEEE (pp. 3569-3574).IEEE.

[9] Liu, Z. (2014). Automatic Control for a Gas System Using PIC Microcontroller.

[10] Mercado, C. U. (2013). Methane Gas and Color Sensor System for Monitoring the Safety of Consumable Pork Meat.

[11] Nograles, H. A. H., Agbay, C. P. D., Flores, I. S. L., Manuel, A. L., \&Salonga, J. B. C. (2014, May). Low cost Internet based wireless sensor network for air pollution monitoring using Zigbee module. In Digital Information and Communication Technology and it's Applications (DICTAP), 2014 Fourth International Conference on (pp. 310-314). IEEE.

[12] Othman, K. A., Li, N., Abdullah, E. H., \&Hamzah, N. (2013). Haze monitoring system in city of kualalumpur using zigbee wireless technology implementation. In World Congress on Engineering (pp. 1448-1452).

[13] Pololu Robotics \&Electronics.Semiconductor sensor for combustible gas. Retrieved from: https://www.pololu.com/file/download/MQ2.pdf?file id=0J309

[14] Preethichandra, D. M. (2013, May).Design of a smart indoor air quality monitoring wireless sensor network for assisted living. In Instrumentation and Measurement Technology Conference (I2MTC), 2013 IEEE International (pp. 1306-1310). IEEE.

[15] Putra, E. H., Hariyawan, M. Y., \&Gunawan, A. (2013). Wireless sensor network for forest fire detection. TELKOMNIKA (Telecommunication Computing Electronics and Control), 11(3), 563-574.

[16] Riley, M. (2012). Programming your home: automate with Arduino, Android, and your computer. Pragmatic Bookshelf.

[17] Sese, J. T., Ibarra, J. B. G., De Castro-Cruz, K., Borita, J. K., Catacutan, N., Jaranilla, K., \& Wong, C. G. (2016, November). Effects of different adsorbent on methane reduction on a garbage bin using MQ4 Gas Sensor. In Control System, Computing and Engineering (ICCSCE), 2016 6th IEEE International Conference on (pp. 455-459).IEEE.

[18] Technical Data For MQ-2 Gas Sensor, Website

[19] http://www.seeedstudio.com/depot/datasheet/MQ-2.pdf

[20] Www.e-gizmo.com

[21] Yu, T. C., \& Lin, C. C. (2015). An intelligent wireless sensing and control system to improve indoor air quality: Monitoring, prediction, and preaction. International Journal of Distributed Sensor Networks. 